\title{
Fracture and shear bond strength analyses of different dental veneering ceramics to zirconia
}

\author{
Alexandre C. Diniz ${ }^{a}$, Rubens M. Nascimento ${ }^{b}$, Julio C.M. Souza ${ }^{c}$, Bruno B. Henriques ${ }^{\text {b,c }}$, Adriana F.P. Carreiro ${ }^{\text {a,* }}$ \\ a School of Dentistry (DOD), Division of Prosthodontics, Universidade Federal do Rio Grande do Norte -UFRN, 59056-000, Natal, Brazil \\ ${ }^{b}$ Materials Engineering Department, Universidade Federal do Rio Grande do Norte - UFRN, Natal, Brazil \\ c Centre for Mechanics and Materials Technologies - CT2M, Department of Mechanical Engineering (DEM), Universidade do Minho, Campus Azurém, 4800-058, Guimarães, Portugal
}

\section{A R T I C L E I N F O}

\section{Article history:}

Received 23 July 2013

Received in revised form 25 November 2013

Accepted 18 January 2014

Available online 24 January 2014

\section{Keywords:}

Dental porcelain

Zirconia

Shear test

Metal-free

Fracture

\begin{abstract}
A B S T R A C T
The purpose of this work was to evaluate the interaction of different layering porcelains with zirconia via shear bond strength test and microscopy. Four different groups of dental veneering porcelains (VM9, Zirkonzanh, Ceramco, IPS) were fused onto forty zirconia-based cylindrical substrates ( $8 \mathrm{~mm}$ in diameter and $12 \mathrm{~mm}$ in height) $(n=10)$, according to the manufacturer's recommendations. Additionally, layered dental porcelain (D-sign, Ivoclar) was fired on ten $\mathrm{Ni}-\mathrm{Cr}$ cylindrical substrates Shear bond strength tests of the veneering porcelain to zirconia or Ni-Cr were carried out at a crosshead speed of $0.5 \mathrm{~mm} / \mathrm{min}$. After the shear bond tests, the interfaces were analyzed by scanning electron microscopy (SEM). The fracture type exhibited by the different systems was also assessed. The results were statistically analyzed by ANOVA at a significant level of $p<.05$. The shear bond strength values of the porcelain-to-NiCr interfaces ( $25.3 \pm 7.1 \mathrm{MPa})$ were significantly higher than those recorded for the following porcelain-to-zirconia systems: Zirkonzanh (18.8 $\pm 1 \mathrm{MPa}$ ), Ceramco $(18.2 \pm 4.7 \mathrm{MPa})$, and IPS (16 $\pm 4.5 \mathrm{MPa})$. However, no significant differences were found in the shear bond strength values between the porcelain-to- $\mathrm{NiCr}$ and porcelain (VM9)-to-zirconia ( $23.2 \pm 5.1 \mathrm{MPa}$ ) groups $(p>.05)$. All-ceramic interfaces revealed mixed failure type, cohesive in the porcelain and adhesive at the interface.

This study demonstrated that all-ceramic systems do not attain yet the same bond strength standards equivalent to metal-ceramic systems. Therefore, despite the esthetic appeal of all-ceramic restorations, the adhesion between the porcelain and zirconia framework is still an issue considering the long term success of the restoration.
\end{abstract}

(c) 2014 Elsevier B.V. All rights reserved.

\section{Introduction}

In oral rehabilitation, dental ceramics are useful for replacing dental crowns, providing esthetic characteristics that are similar to those of natural teeth [1-3]. This interesting application is mainly based on the optical properties and chemical stability of the ceramic materials [1-4]. A match of properties between the different material layers used to build a prosthetic crown improves the performance of that dental restorative system in the oral cavity. In fact, dental ceramics have undergone extensive study in recent years because of their attractive properties. Additionally, some improvements in their composition and properties have been reported in the literature [1-6].

Yttria-stabilized zirconia polycrystal (Y-TZP) has been applied since the 1990s in dentistry to synthesize frameworks of dental-fixed prostheses by slip-casting or CAD-CAM techniques. Y-TZP reveals a higher mechanical strength than that of feldspar-based porcelains or alumina

\footnotetext{
* Corresponding author at: Universidade Federal do Rio Grande do Norte, Departamento de Odontologia (DOD), Avenida Senador Salgado Filho, 1787, CEP: 59056-000, Natal, Brazil. Tel.: + 5584 3215-4135; fax: + 5584 3215-4104.

E-mail address: adrianadafonte@hotmail.com (A.F.P. Carreiro).
}

[7-11]. Such mechanical strength results from the phase transformation from a monoclinic to a tetragonal structure [9-11]. Previous studies have revealed flexural strength values for Y-TZP ranging from 900 up to $1200 \mathrm{MPa}$ and a fracture toughness of $9-10 \mathrm{MPa} \cdot \mathrm{m}^{1 / 2}$ [9-11]. Retrospective in vivo studies have revealed no fracture of Y-TZP frameworks over short [6] or medium [10,12] periods of evaluation. However, failures in dental porcelain-to-zirconia assemblies due to fractures along the porcelain-to-zirconia interface have been reported in previous studies [10-14]. Some findings have revealed failures at $8 \%$ of the dental porcelain-to-zirconia interfaces over a period of 36 months compared with $13 \%$ over 38 months [10-14]. Another study revealed failures at $15 \%$ of the dental porcelain-to-zirconia interfaces over a period of 24 months and 25\% over 31 months [12]. However, a low failure rate $(2.7-5.5 \%)$ has been revealed for metal-ceramic systems over periods of 10 and 15 years $[15,16]$.

The clinical assessment of dental restorative systems is relevant to predicting the long-term performance of oral rehabilitation systems [17]. However, in vitro studies must be conducted to evaluate failures in the different situations that could occur from the processing of the structural material up to its use in the oral cavity. Thus, the chipping of veneering porcelains to frameworks can be associated with several 
factors, such as: the veneering thickness and occlusal support [18]; the morphology of the circular finishing line [19]; adhesive forces between the framework and the veneering [4,20-37]; the mismatch of properties between the material layers $[1,14,18]$; the sensitivity of the technique used for porcelain application; and the residual stresses that are influenced by the cooling cycle during the veneering process $[4,12,13,36-40]$. Concerning ceramic materials, mechanical failures and the propagation of cracks through the dental porcelain when fused to metal or zirconia frameworks have been frequently reported in the literature $[3,4,8-11,14,18]$. There are a few in vivo studies that reveal details of the mechanical behavior of dental ceramics and other in vitro studies involving microscopic analysis of ceramic fractures $[14,41]$.

The main aim of this work was to evaluate the shear bond strength of different layered dental porcelains to zirconia, followed by microscopic analysis of fracture surfaces, and to compare the shear bond strength of veneering porcelains to zirconia to that of veneering porcelain to metal. The null hypothesis of this study was that the shear bond strength values of veneering porcelains to zirconia and to metal were similar.

\section{Materials and methods}

\subsection{Synthesis of specimens}

Forty porcelain-zirconia specimens were synthesized by fusing 4 different dental feldspar-based porcelains (VM9, Zirkonzanh, Ceramco, IPS) onto cylindrical zirconia substrates (frameworks). The structural materials used to synthesize the specimens are shown in Table 1. Cylindrical ceramic substrates ( $8 \mathrm{~mm}$ in diameter and $12 \mathrm{~mm}$ in height) were produced from yttria-stabilized tetragonal zirconia polycrystal (Zirkonzahn; Gais, Italy) by CAD-CAM method (Biodenta; Berneck, Switzerland). Porcelain-to-zirconia assemblies were divided into 4 groups $(n=10)$. However, dental veneering porcelain (D-sign, Ivoclar Vivadent; Schaan, Liechtenstein) was fused onto 10 cylindrical $\mathrm{Ni}-\mathrm{Cr}$ substrates to synthesize ceramic-to-metal assemblies (control group). "The power analysis performed in order to determine the number of samples to be used in each group, indicated that using 10 specimens per group $(n=10)$ resulted in a power of $98 \%$, which is higher than a power of $80 \%$, usually considered to be sufficient power".

For ceramic-to-metal systems, $\mathrm{Ni}$-Cr cylindrical substrates $(8 \mathrm{~mm}$ in diameter and $12 \mathrm{~mm}$ in height) were produced by the lost-wax casting method. After casting, the cylindrical substrates were finished by rubbing an alumina cone-shaped tool bit that was coupled to a highspeed rotating machine. The substrate area for porcelain application was grit-blasted by airborne-particle abrasion with alumina $\left(\mathrm{Al}_{2} \mathrm{O}_{3}\right)$ particles ( $110 \mu \mathrm{m}$ in diameter) under a pressure of $0.41 \mathrm{MPa}$ for $15 \mathrm{~s}$ and at $10 \mathrm{~mm}$ from the surface. Before the application of the porcelain, the substrates were cleaned in propyl alcohol for $10 \mathrm{~min}$ and in distilled water for 1 min using an ultrasonic bath and were then dried at room temperature. A bonding porcelain (liner) was applied onto the zirconia substrates before the application of the veneering porcelain. The veneering porcelain powder was mixed with distilled water at a 2:1 ratio to obtain a porcelain paste that was applied in layers $(8 \mathrm{~mm}$ in diameter and $4 \mathrm{~mm}$ in height) onto the top of the surface area of the substrate using a stainless steel mold (Fig. 1A-B). The shrinkage of the porcelain occurring in the first firing cycle determined the application of a second porcelain layer on top of the first porcelain layer, followed by another firing cycle. The compaction and thermal treatment (firing cycle) of the veneering porcelains were in accordance with the manufacturer's recommendations (Table 2). The specimens are shown in Fig. 1C-D.

\subsection{Shear bond tests and microscopic analysis of fracture areas}

The cylindrical specimens were placed in a stainless steel apparatus for the shear bond tests (Fig. 1). The shear bond tests were performed at room temperature by applying a load on the ceramic area in line with the plane of the interface at a crosshead speed of $0.5 \mathrm{~mm} / \mathrm{min}$ by using an Autograph Shimadzu AG-X 250 kN (Shimadzu; Japan). A stainless steel piston $[34,36]$ was coupled to the shear test machine to load the specimen into the stainless steel jig. The shear bond strength (MPa) was obtained by the relation between the highest recorded fracture force $(\mathrm{N})$ and the area of the adherent porcelain $\left(\mathrm{mm}^{2}\right)$. The results were statistically analyzed via one-way analysis of variance (ANOVA) with a significance level of $\mathrm{p}<0.05$ using the SPSS 17.0 software for Windows (Chicago, IL, USA). Tukey test was applied to compare the results between the groups.

After the shear bond tests, the fractured areas of the specimens were sputter-coated with a gold layer of $20 \mathrm{~nm}$ and inspected by scanning electron microscopy (XL-30 SEM; Philips) at $20 \mathrm{kV}$ under secondary electrons (SE) mode. The failure pathways of the specimens were inspected.

\section{Results}

The shear bond strength values of the metal-free and ceramic-tometal interfaces are shown in Table 3. Shear strength values recorded for veneering porcelains to zirconia substrate ranged from 16 up to $23 \mathrm{MPa}$ (Table 3). No significant differences among three of the four ceramic-to-zirconia groups (CE, EM and IC groups) were found, as shown in Tables 3 and $4(p>.05$; power $=98 \%)$. The IC group revealed the lowest variability in the shear bond strength values, which might be related to greater homogeneity between the specimens of a group (Table 3 ).

The shear bond strength values of D-sign porcelain to $\mathrm{Ni}-\mathrm{Cr}$ (CG $25.3 \pm 7.1 \mathrm{MPa}$ ) were significantly higher than those recorded for the Ceramco (CE - 18.2 $\pm 4.7 \mathrm{MPa})$, IPS (EM - 16.2 $\pm 4.5 \mathrm{MPa}$ ) and Zirkonzahn (IC $-18.8 \pm 1.0 \mathrm{MPa}$ ) groups. The Tukey multiple comparison test indicated no significant differences between porcelainto-Ni-Cr (CG) and VM9 porcelain-to-zirconia (VM - 23.2 $\pm 3.8 \mathrm{MPa}$ ) groups.

After the shear bond test, the fracture surfaces were inspected by scanning electron microscopy (Fig. 2A). Those surfaces revealed

Table 1

Coefficient of thermal expansion and mechanical properties of the materials used in this study according to the manufacturer's instructions and previous studies.

\begin{tabular}{|c|c|c|c|c|}
\hline Group & Material/manufacturer & $\mathrm{CTE}^{\mathrm{a}}\left(.10^{-6} \cdot \mathrm{K}^{-1}\right)$ & Elastic modulus (GPa) & Fracture toughness $\left(\mathrm{MPa} \cdot \mathrm{m}^{1 / 2}\right)$ \\
\hline $\mathrm{CE}$ & Ceramco PFZ porcelain/Dentsply; USA & 10.5 & $68 \pm 2$ & $0.9-1.2$ \\
\hline IC & Zirkonzahn ICE porcelain/Zirkonzahn; Gais, Italy & 9.6 & 65 & 0.8 \\
\hline VM & VM9 porcelain/Vita Zahnfabrik; Bad Säckingen, Germany & $8.8-9.2$ & 65 & 0.8 \\
\hline EM & IPS e.max ceram porcelain/Ivoclar-Vivadent; Schaan, Liechtenstein & $9.8 \pm 0.25$ & $65 \pm 10$ & 0.7 \\
\hline CG & D-Sign porcelain/Ivoclar Vivadent; Schaan, Liechtenstein & $12.6 \pm 0.5$ & 67 & $0.93 \pm 0.1$ \\
\hline $\mathrm{C}$ & Zirkonzahn/Y-ZTP/Zirkonzahn; Gais, Italy & 10.5 & 210 & 9 \\
\hline M & NiCr alloy, Wironia Light/fBego; Bremen, Germany & $13.8-14.1$ & $200 \pm 12$ & - \\
\hline
\end{tabular}

${ }^{\text {a }}$ CTE - coefficient of linear thermal expansion. 

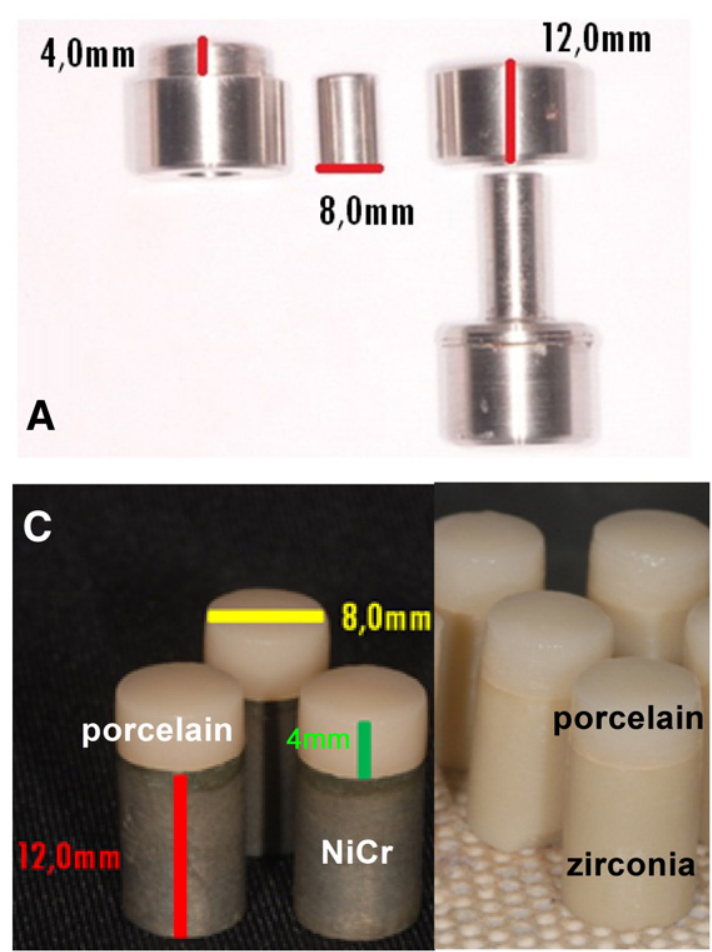
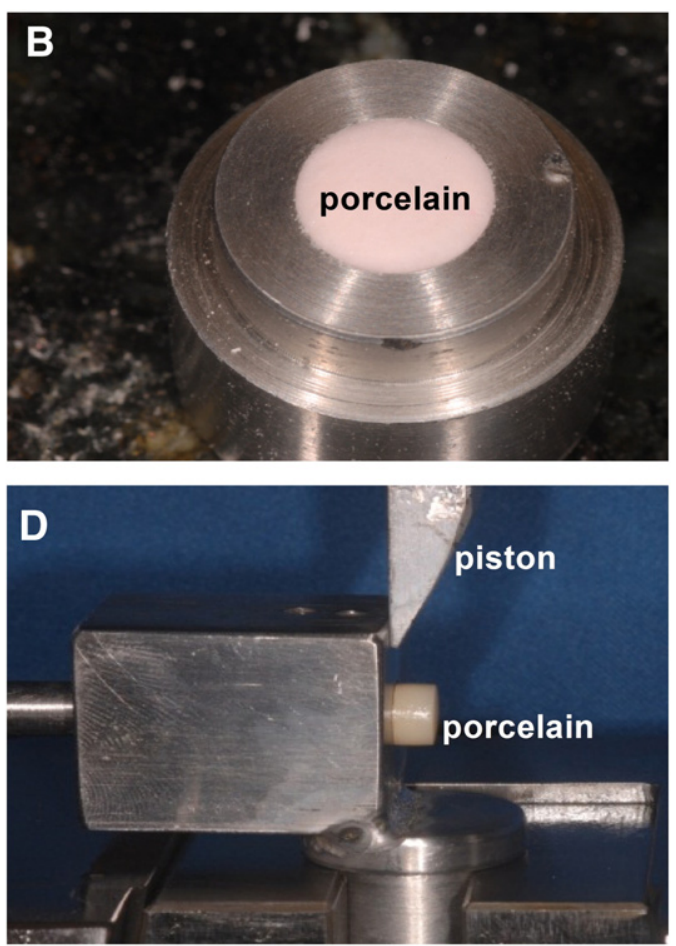

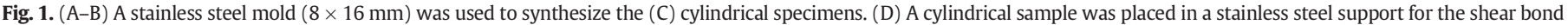
tests (crosshead speed of $0.5 \mathrm{~mm} / \mathrm{min}$ ).

predominant mixed cohesive/adhesive failure modes for both zirconia and metal based groups. As shown in Fig. 2A, the fracture surface of a specimen of the CE group revealed a mixed fracture surface, cohesive within the veneering porcelain and adhesive at the zirconia surface. Arrows in Fig. 2B indicate the direction of the layer rupture by crack propagation through the veneering porcelain in group CE. The inspection of the fracture surfaces of the different groups also revealed the presence of large pores within the veneering porcelain (Fig. 2C-F). The implications of such occurrence will be further discussed ahead in this paper.

\section{Discussion}

The results of the present study support the rejection of the null hypotheses. They showed significant differences between the shear bond strength of zirconia and its veneering porcelains as well as the shear bond strength of the $\mathrm{NiCr}$ alloy and its veneering porcelain. Ashkanani et al. (2008) [23] reported the same findings for shear bond strength tests between metal-porcelain and zirconia porcelain systems. By contrast, Al-Dohan et al. (2004) [27] found no significant differences in the shear bond strength of veneering porcelains to zirconia and to metallic substructures. In the present study, only the mean shear bond strength value of VM9 porcelain fused to zirconia (VM) was similar to that of dental porcelain fused to $\mathrm{NiCr}$ (CG). The remaining porcelain fused to zirconia groups (CE, EM and IC) showed significantly lower bond strength values as compared to the VM and CG groups. The shear bond strength results of this study are in agreement with those reported by Fisher et al. (2009) [36]. They reported the VM9 porcelain as having the highest shear bond strength among 11 veneering porcelains bonded to zirconia substructures and the IPS e.max as yielding one of the least shear bond strength values. The absolute bond strength values were different, though. This can be very well explained by the difference in parameters such as materials, geometry of the specimens and setup [19,28,31,35,36]. The same authors found that the shear bond strength values between the veneering porcelains and the zirconia substrates had a slight correlation to the product of the difference between the coefficient of thermal expansion of veneering porcelains and zirconia $(\Delta \alpha)$ and the difference between the glass transition temperature and room temperature ( $\Delta \mathrm{T}$, in $\mathrm{K}), \Delta \alpha \Delta \mathrm{T}$. The highest shear bond strength values were obtained for $\Delta \alpha \Delta \mathrm{T} \approx 1000$ $\times 10^{-6}$. Correspondingly, the VM9 porcelain exhibited a value of

Table 2

Thermal treatment (firing cycle) of veneering porcelain on zirconia and NiCr frameworks according to the manufacturer's recommendations.

\begin{tabular}{|c|c|c|c|c|c|c|}
\hline \multicolumn{2}{|c|}{ Porcelain } & Pre-heating temperature $\left({ }^{\circ} \mathrm{C}\right)$ & Pre-heating time ( $\mathrm{min}$ ) & Heating rate $\left({ }^{\circ} \mathrm{C} / \mathrm{min}\right)$ & Firing temperature $\left({ }^{\circ} \mathrm{C}\right)$ & Holding time (min) \\
\hline \multicolumn{7}{|c|}{ Liner for metal-free/opaque for D-Sign porcelain } \\
\hline CE & Ceramco PFZ & 450 & 5 & 60 & 930 & 1 \\
\hline IC & ICE Keramik & 350 & 5 & 55 & 920 & 2 \\
\hline VM & Vita VM9 & 500 & 6 & 55 & 930 & 1 \\
\hline EM & IPS e.max Ceram & 400 & 4 & 60 & 960 & 1 \\
\hline CG & D-Sign & 500 & 6 & 50 & 900 & 1 \\
\hline \multicolumn{7}{|c|}{ Dentin } \\
\hline CE & Ceramco PFZ & 450 & 5 & 60 & 900 & 1 \\
\hline IC & Ice Keramik & 300 & 6 & 55 & 820 & 1 \\
\hline VM & Vita VM9 & 500 & 6 & 55 & 910 & 1 \\
\hline EM & IPS e.max Ceram & 400 & 4 & 50 & 750 & 1 \\
\hline CG & D-Sign & 500 & 6 & 50 & 900 & 1 \\
\hline
\end{tabular}


Table 3

Shear bond strength values of dental veneering porcelains to zirconia and $\mathrm{NiCr}$.

\begin{tabular}{llllllllll}
\hline Group & $\mathrm{N}$ & Mean $^{\mathrm{a}}(\mathrm{MPa})$ & Std & Min & Max & P.E. & \multicolumn{2}{c}{$\mathrm{Cl}(95 \%)$} \\
\cline { 6 - 9 } & & & & & & & I.L. & S.L. \\
\hline EM & 10 & $16.16^{\mathrm{a}}$ & 4.51 & 7.24 & 20.32 & 1.43 & 13.36 & 18.96 \\
CE & 10 & $18.19^{\mathrm{a}}$ & 4.74 & 8.64 & 23.17 & 1.50 & 15.25 & 21.13 \\
IC & 10 & $18.79^{\mathrm{a}}$ & 1.02 & 16.98 & 21,11 & 0.32 & 18.16 & 19.42 \\
VM9 & 10 & $23.24^{\mathrm{b}}$ & 3.76 & 13.02 & 26.54 & 1.19 & 20.91 & 25.58 \\
GC & 11 & $25.27^{\mathrm{b}}$ & 7.10 & 15.24 & 36.40 & 2.14 & 21.07 & 29.47 \\
\hline
\end{tabular}

${ }^{a}$ Values with the same letter revealed no significant differences with Tukey test, $p<.05$.

$868.4 \times 10^{-6} \pm 238.74 \times 10^{-6}$ and the IPS e.max exhibited a value of $184.6 \times 10^{-6} \pm 103 \times 10^{-6}$. No information was provided on this parameter for the porcelains Ceramco PFZ and Zirkonzahn ICE, but following this rationale, the values for $\Delta \alpha \Delta \mathrm{T}$ are expected to significantly differ from $\approx 1000 \times 10^{-6}$. In addition, Cömlekoğlu et al. (2008) [42] reported that the Ceramco PFZ yielded the lowest shear bond strength values among the 4 different veneering porcelains to zirconia substrates. The results of this study are also consistent with those of Özkurt et al. (2009) [34], which reported higher shear bond strength values for VM9 porcelain, followed by that of the IPS e.max ceramic and finally to that of ICE Zirkonzahn porcelain, all bonded to a Zirkonzahn zirconia substrate.

In previous studies, dental porcelain fused to $\mathrm{NiCr}$ alloys have shown slightly higher shear bond strength values compared with those of porcelains fused to yttria-stabilized tetragonal zirconia [28,30-32]. In fact, the use of novel veneering porcelains and surface treatments on zirconia frameworks has improved the mechanical behavior of porcelain-to-zirconia interfaces [32,37,41]. Considering the treatment of the zirconia surface, a previous study demonstrated that the application of a bonding porcelain (liner) prior to the veneering porcelain increased the risk of failures at the porcelain-to-zirconia interfaces [37]. Also, airborne-particle abrasion on zirconia can be more efficient for increasing the shear bond strength of the interfaces compared with that of the liner application [37]. The mean and SD values of the shear bond strength recorded on porcelain-to-zirconia interfaces ranged from $27.87 \pm 3.59 \mathrm{MPa}$ (with liner application) up to $36.63 \pm 2.96 \mathrm{MPa}$ (with $110 \mu \mathrm{m}$ alumina airborne-particle abrasion) [37]. However, another previous study found that airborne-particle abrasion is not necessary to enhance the shear bond strength of the veneering ceramics to ceria-stabilized tetragonal zirconia polycrystal that was alloyed with alumina (Ce-TZP/A) [27]. That study also reported a negative effect of liners on the shear bond strength of veneering ceramics to Ce-TZP/A, although the application of liners to Y-TZP had no significant effect [30]. Significant differences in the shear bond strength of veneering porcelains to Ce-TZP/A were found between polished $(21 \pm 3.9 \mathrm{MPa}$ without liner, $27.1 \pm 5.1 \mathrm{MPa}$ with liner) and airborne-particleabraded specimens $(23.95 \pm 1.97 \mathrm{MPa}$ without liner, $17.7 \pm 2.2 \mathrm{MPa}$ with liner) [30]. The shear bond strength of different veneering ceramics to zirconia ranged from $14.2 \pm 1.7 \mathrm{MPa}$ (IPS e.max with liner) to $27.5 \pm 4.2 \mathrm{MPa}$ (VITA VM 9).

Regarding the use of different veneering porcelains and liners, a match of properties between the structural materials (porcelain and framework materials) is important for chemical bonding during thermal treatment as well as for the mechanical strength behavior of the interfaces under loading. For instance, a match of coefficient of linear thermal expansion (CTE) between veneering porcelain and zirconia decreases residual stresses at the interface $[3,4,21,39,40]$. By contrast, an

Table 4

Analysis of variance of the results.

\begin{tabular}{lrrlll}
\hline Variation & Square sum & d.f. & Square average & $(\mathrm{F})$ & $p$ \\
\hline Between groups & 596.034 & 4 & 149.008 & 6.674 & $<0.001$ \\
Within group & 1027.086 & 46 & 22.328 & & \\
Total & 1623.119 & 50 & & & \\
\hline
\end{tabular}

inappropriate mismatch in the CTE can promote the formation of cracks at the interface, leading to a catastrophic fracture of the veneering porcelains $[3,14,33,40]$. Additionally, non-recommended rates of heating and cooling of the veneering porcelains during the thermal treatment induce residuals stresses and the formation of cracks $[21,39,40]$.

Materials are often submitted to thermocycling tests to evaluate whether the temperature alteration, simulating those occurring in the oral cavity, affect the adhesive strength of two materials. These tests were not performed in this study, though. Ashkanani et al. (2008) [23] evaluated the thermal cycling effect on the shear and flexural bond strength of veneering porcelain to zirconia and veneering porcelain to noble alloy. They found that the thermocycling didn't have a significant effect on the strength of both groups.

The fracture surface analysis of the specimens revealed the presence of pores to a significant extent within the porcelain. These pores are formed within the porcelain during firing cycle and it can be caused by the incorrect use of powder/water proportions during the handling compaction of the veneering porcelain. According to previous studies, ceramic fracture has been frequently associated with the presence of pores and cracks, which can cause variability in the shear bond strength [5,21-23]. These defects provide locations of stress concentration and crack propagation that can also determine the ceramic fracture pathways, whether they are cohesive or adhesive [4,21,22]. The application of heat pressed veneering porcelains to metallic or ceramic substrates has been shown to decrease dramatically the formation of pores within the porcelain and to provide enhanced bond strength between the two materials [3,20-22].

There are several available ways to determine the bond strength between restorative dental materials. The shear tests, the Schwickerath crack initiation test used in ISO 9693:1999, the three-point-flexure test, the four-point-flexure test and the biaxial flexure test are among the most commonly used mechanical tests. The shear bond strength test was selected for this study due to a couple of important features: the results are not influenced by Young's modulus of the substrate $[17,18]$; and because it is simple and easy to perform [28]. Therefore, it has been often used when the in-vito analysis on the bond strength between dental restorative materials is performed. There are some important aspects about this test that must be considered when analyzing the results: great variations in results are a characteristic of this type of test; the results cannot be extrapolated directly to clinical situations; and due to geometrical differences of the specimens employed in the different bond strength tests, no direct comparison should be made with their results $[3,35,36,28]$. As an example, the configuration of the shear test device itself can promote significant differences in results. Van Noort at al. (1989) [43] and DeHoff et al. (1995) [44] showed that the geometry of the edge of the pushing rod can have a great influence on the stresses generated at the veneering porcelain and consequently on the bond strength results.

Specimens were classified under their failure mode as adhesive, cohesive or mixed: (1) adhesive, if no remnants of porcelain were found in the metal or zirconia surface; (2) cohesive, if fractures occurred within the porcelain side; (3) mixed, if remnants of porcelain were found in the metal/zirconia surface. A combined mode of fracture (cohesive and adhesive) seems to be the main form of veneering porcelain detachment from zirconia frameworks [14,23], as was noticed in this study. The reported failure modes are in agreement with those reported by Al-Dohan et al. (2004) [28] in their study involving 4 veneering porcelains to zirconia cores. Choi BK et al. (2009) [45] also reported mixed cohesive/adhesive failures with only small remnants of porcelain attached to the zirconia substrate. On the other hand, Ashkanai et al. (2008) [23] reported that specimens failed cohesively within the veneering porcelain. The failure modes reported in these in-vitro studies reflect to some extent the behavior of the zirconia-based restorations in the oral cavity, which have been showing failures in the form of porcelain chipping (Swain et al., 2009) [14]. Aside from the fact that the geometry of the specimens used in in-vitro studies do not reflect the 

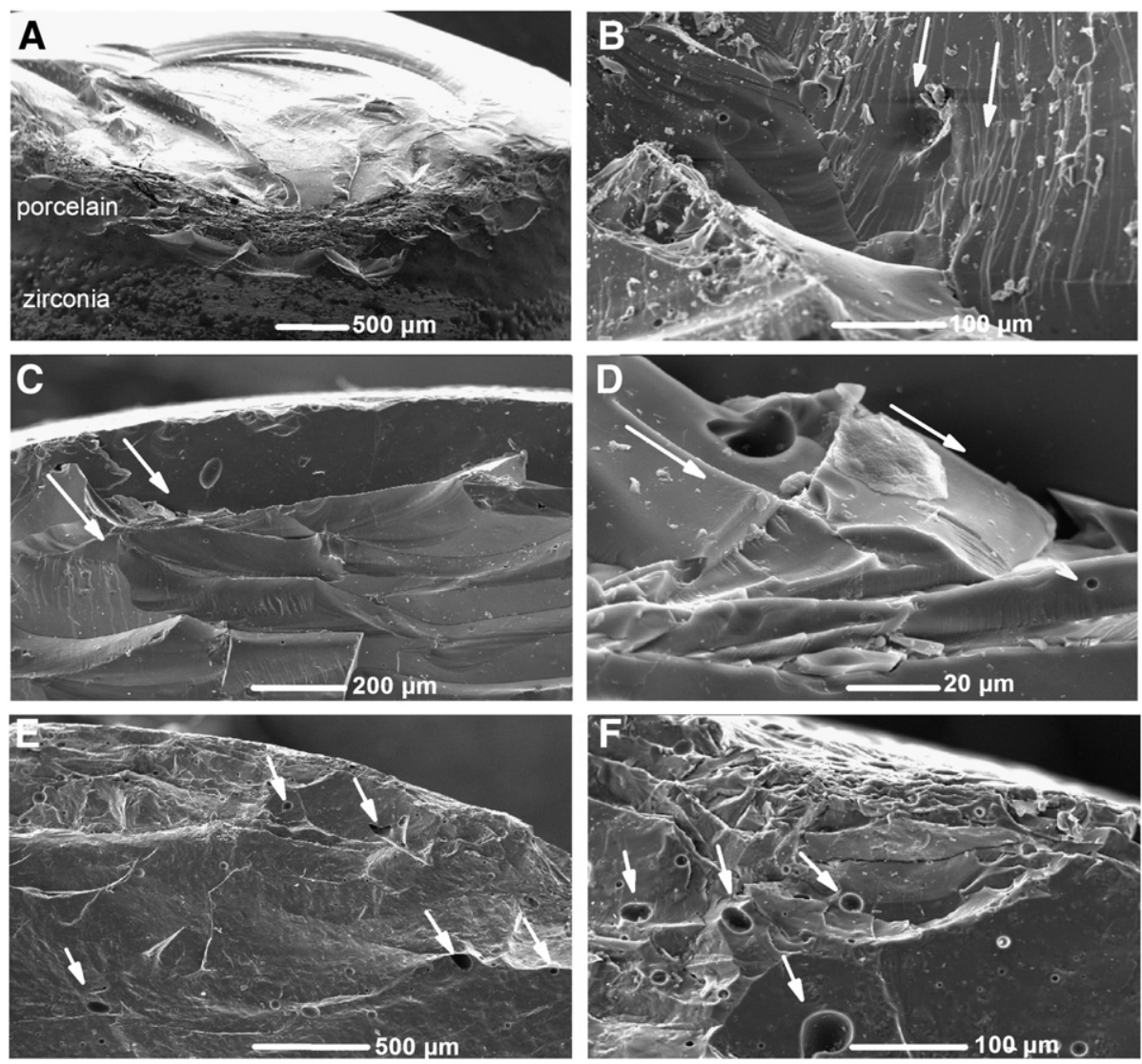

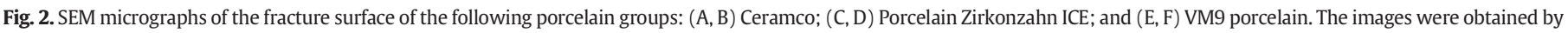
secondary electrons (SE) mode at $20 \mathrm{kV}$.

geometry of dental crowns, the failure mode demonstrated in clinical situations and in-vitro experiments are both related to the problem of poor cohesion strength of the porcelain. Therefore, the overall strength of zirconia-porcelain systems would be undoubtedly enhanced if stronger porcelains are developed.

The present in vitro study reveals some limitations related to the technical sensitivity of several commercial veneering porcelains to zirconia or NiCr. Also, the oral cavity's structures are subjected to complex stress fields that are very difficult to reproduce in in-vitro conditions. The shear bond strength tests are a useful tool to assess the bonding properties between different materials used in restorative dentistry, but no direct extrapolations can be made considering the behavior of these materials under clinical conditions. Considering the findings revealed in this study, some suggestions can be considered in further research work such as: assessment of bond strength properties between porcelain-zirconia systems using complementary test configurations with different loading conditions. Additionally, the study of novel porcelain formulations and bonding agents are also suggested as part of the continuous effort for the improvement of the global mechanical behavior of porcelain-zirconia restorative systems.

\section{Conclusions}

This study assessed the shear bond strength of different porcelains to a zirconia substrate. Results were compared to those obtained for porcelain fused to a metallic substrate. The following conclusions can be drawn:

1. The shear bond strength of the veneering porcelains to the zirconia substrates was significantly lower than that recorded for metalceramic control group $(\mathrm{p}<0.05)$;

2. The porcelain Vita VM9 applied to a zirconia substrate showed the highest shear bond strength value among the porcelain-zirconia systems $(p<0.05)$. The bond strength was significantly different from those of the other porcelain-zirconia systems, but not from that of the metal-ceramic control group.

3. The fracture surface analyses of the all-ceramic systems revealed mainly a mixed failure mode, cohesive in the porcelain and adhesive at the interface;

\section{Acknowledgments}

The authors acknowledge the financial support provided by CTPETROINFRA, FINEP/LIEM and CAPES (Brazil).

\section{References}

[1] K.J. Anusavice, Philips' Dental Materials, 2005. 608-613.

[2] I. Denry, J.A. Holloway, Ceramics for dental applications: a review, Mater. 3 (2010) 351-368.

[3] K.C. Cheung, B.W. Darvell, Dent. Mater. 18 (2002) 163-173.

[4] J.C.M. Souza, A.E. Martinelli, R.M. Nascimento, Surf. Coat. Technol. 205 (2010) 787-792.

[5] A.R. Studart, F. Filser, P. Kocher, H. Lüthy, L.J. Gauckler, Dent. Mater. 23 (2007) $115-123$.

[6] B.F.A. Sturzenegger, H. Luthy, M. Schumacher, O. Loeffel, F. Filser, P. Kocher, Acta Med. Dent. Helv. 5 (2000) 131-139.

[7] F. Zarone, S. Russo, R. Sorrentino, Dent. Mater. 27 (2011) 83-96.

[8] M. Guazzato, A. Albakry, S.P. Ringer, Dent. Mater. 20 (2004) 441-448.

[9] M. Guazzato, A. Albakry, S.P. Ringer, Dent. Mater. 20 (2004) 449-456.

[10] J. Tinschert, K.A. Schulze, G. Natt, P. Latzke, N. Heussen, H. Spiekermann, Int. J. Prosthodont. 21 (2008) 217-222.

[11] J. Tinschert, D. Zwez, R. Marx, K.J. Anusavice, J. Dent. 28 (2000) 529-535.

[12] A.J. Raigrodski, G.J. Chiche, N. Potiket, J. Prosthet. Dent. 96 (2006) 237-244.

[13] I. Sailer, A. Feher, F. Filser, Quintessence Int. 37 (2006) 685-693.

[14] M.V. Swain, Acta Biomater. 5 (2009) 1668-1677.

[15] M. Walter, P.D. Reppel, K. Boning, W.B. Freesmeyer, J. Oral Rehabil. 26 (1999) 91-96.

[16] J. Coornaert, P. Adriaens, J. De Boever, J. Prosthet. Dent. 51 (1984) 338-342.

[17] H.J. Conrad, W.J. Seong, I.J. Pesun, J. Prosthet. Dent. 98 (2007) 389-404.

[18] B.R. Lawn, J.J. Lee, Acta Biomater. 5 (2009) 2213-2221. 
[19] I.A. Hammad, Y.F. Talic, J. Prosthet. Dent. 75 (1996) 602-608.

[20] G. Isgrò, P. Pallav, J.M. Van Der Zel, A.J. Feilzer, J. Prosthet. Dent. 90 (2003) 465-473.

[21] B. Henriques, F.S. Silva, Mater. Sci. Eng. A 528 (2011) 1415-1420.

[22] B. Henriques, F.S. Silva, J. Mech. Behav. Biomed. Mater. 4 (2011) 1718-1726.

[23] H.M. Ashkanani, A.J. Raigrodski, B.D. Flinn, H. Heindl, L.A. Mancl, J. Prosthet. Dent. 100 (2008) 274-284.

[24] B. Henriques, D. Soares, F.S. Silva, J. Mech. Behav. Biomed. Mater. 12 (2012) 83-92.

[25] B. Henriques, D. Soares, F. Silva, Mater. Sci. Eng. C 32 (2012) 2374-2380.

[26] B. Henriques, M. Gasik, D. Soares, F. Silva, J. Mech. Behav. Biomed. Mater. 13 (2012) 206-214.

[27] B. Henriques, D. Soares, F. Silva, Mater. Sci. Eng. C 33 (2013) 557-563.

[28] H.M. Al-Dohan, P. Yaman, J.B. Dennison, M.E. Razzoog, B.R. Lang, J. Prosthet. Dent. 91 (2004) 349-355.

[29] M. Rosentritt, M. Behr, G. Handel, J. Oral Rehabil. 30 (2003) 873-877.

[30] J. Fischer, B. Stawarzcyk, I. Sailer, C.H.F. Hämmerle, J. Prosthet. Dent. 103 (2010) 267-274.

[31] P.C. Guess, A. Kulis, S. Witkowski, M. Wolkewitz, Y. Zhang, J.R. Strub, Dent. Mater. 24 (2008) 1556-1567.

[32] J.-T. Kim, S.-A. Cho, J. Prosthet. Dent. 101 (2009) 101-106.
33] A. Saito, F. Komine, M.B. Blatz, H. Matsumura, J. Prosthet. Dent. 104 (2010) 247-257.

[34] Z. Ozkurt, E. Kazazoglu, A. Unal, Dent. Mater. J. 29 (2) (2010) 138-146.

[35] M. Dundar, M. Ozcan, B. Gökçe, E. Cömlekoğlu, F. Leite, L.F. Valandro, Dent. Mater. 23 (2007) 630-636

[36] J. Fischer, P. Grohmann, B. Stawarzcyk, Dent. Mater. J. 27 (2008) 448-454

[37] J.-T. Kim, H.-P. Lim, Y.-J. Park, M.-S. Vang, J. Prosthet. Dent. 105 (2011) 315-322.

[38] J. Fischer, B. Stawarzcyk, A. Trottmann, C.H. Hämmerle, Dent. Mater. 25 (2009) 419-423.

[39] M.J. Cattell, R.P. Palumbo, J.C. Knowles, R.L. Clarke, D.Y. Samarawickrama, J. Dent. 30 (2002) 161-169.

[40] F. Komine, A. Saito, K. Kobayashi, M. Koizuka, H. Koizumi, H. Matsumura, J. Oral Sci. 52 (2010) 647-652

[41] B. Al-Amleh, K. Lyons, M. Swain, J. Oral Rehabil. 37 (2010) 641-652.

[42] M.E. Cömlekoğlu, M. Dündar, M. Özcan, M.A. Güngör, B. Gökçe, C. Artunç, J. Dent. 36 (2008) 822-827.

[43] R. Van Noor, S. Noroozi, I.C. Howard, G. Cardew, 76 (1996) 140-144.

[44] P.H. DeHoff, A.J. Anusavice, Z. Wang, Dent. Mater. 11 (1995) 126-131.

[45] B.K. Choi, J.S. Han, J.H. Yang, J.B. Lee, S.H. Kim, J. Adv. Prosthodont. 1 (2009) 129-135. 